Psychology of Language and Communication 2016, Vol. 20, No. 3

DE GRUYTER

宣

DOI: $10.1515 /$ plc-2016-0012

BARBARA BOKUS, PIOTR KAEOWSKI

University of Warsaw

\title{
FIGURATIVE LANGUAGE PROCESSING: IRONY. INTRODUCTION TO THE ISSUE
}

\begin{abstract}
Processing of figurative (nonliteral) language is the focus of this special issue of Psychology of Language and Communication. The main theme is irony, which has been called "the ethos of our times" (Wampole, 2012). The texts presented here consider irony from many different angles, thus expanding the psycholinguistic perspective to include problems of key importance for understanding the phenomenon. All of these texts open up new questions on irony comprehension and production. The next special issue (to be published in 2017) will discuss research on a different type of nonliteral language: metaphors.
\end{abstract}

Key words: nonliteral language, irony, participant structure, structure of participation

The present special issue of Psychology of Language and Communication is the first one of two devoted to the topic of figurative (nonliteral) language processing. The main theme of this issue is irony. The authors of the papers presented here consider irony from many different angles, in an effort to expand the psycholinguistic perspective to include issues of key importance for understanding the phenomenon.

Irony has been called "the ethos of our times". In an increasingly uncertain and changing world, irony is no longer a purely linguistic mechanism but is becoming a way of thinking and a strategy for interacting with others (Wampole, 2012). In view of its growing importance in daily life, one could say that studying irony provides knowledge about ourselves.

Kreuz and Roberts (1993) distinguish four types of irony: (a) Socratic irony, or adopting a position of feigned ignorance as a rhetorical strategy;

Address for correspondence: Barbara Bokus, Faculty of Psychology, University of Warsaw, ul. Stawki 5/7, 00-183 Warsaw, Poland. E-mail: bokus@al.uw.edu.pl 
(b) dramatic irony, when the audience of a text knows more about the characters than the characters themselves; (c) irony of fate, or situational irony, and (d) verbal irony. The research presented in this issue concerns this last type of irony. Over the centuries, verbal irony seems to have garnered the most attention. What is interesting, however, is that disputes over its essence, beginning as far back as antiquity (cf. the review by Colston \& Gibbs, 2007), continue to this day, fueled by progress in interdisciplinary research. Thus, psycho- and sociolinguistic studies on irony draw upon disciplines including linguistics, literary studies, sociology, psychology, and neuroscience (involving the use of neuroimaging methods), with each of these approaches focusing on slightly different aspects of this phenomenon. The papers collected in the present issue offer a broader, multi-faceted approach to irony.

Verbal irony always appears in a specific discourse situation. Roughly speaking, we can distinguish two levels of said situation: the participant structure and the structure of participation. Let us explain the difference. The participant structure (Philips, 1972) refers to the relations between the actors of a given event (that is, the discourse participants). These relations are considered in terms of the participants' social identity, their social status, and such personal features as age, gender, scope of knowledge, and lived experience. A change in relations between participants in these different aspects causes a change in the participant structure. One important criterion in these relations is their symmetry or asymmetry.

The structure of participation refers to the interaction of the discourse subjects (participants). Every participant contributes to this process. The structure of participation forms as the realization of possibilities contained in the participant structure and emerges in the course of interaction (Tannen, 1979; Shugar, 1995), taking place, for example, in situations of direct face-to-face contact or in computer-mediated communication (as will be shown in the paper by Aguert and collaborators in this issue).

The papers in the present issue draw attention to irony as a message that is both received and produced. Hence, you will find here papers on studies of situations of irony comprehension and use as well as factors that play a role in these processes. Research on irony involves a number of difficulties linked to the complexity of the social situation in which it occurs. It is often a subtle phenomenon, relying on contextual hints or suggestions. Experiments studying irony use and processing should therefore try to achieve the greatest possible external accuracy of the research design.

In their paper "Producing irony in adolescence: A comparison between face-to-face and computer-mediated communication" Marc Aguert (University of Caen Normandy, PALM), Virginie Laval (University of Poitiers, CeRCA), and Nadia Gauducheau, Hassan Atifi, Michel Marcoccia (all three from the Troyes Technological University, Tech-CICO, ICD) discuss how the communication medium, in this case the Internet, affects irony use. Analyzing corpuses of teenagers' contributions 
(thus also taking into account the role of the participant structure) to an online forum and comparing them with arranged situations of free conversation among them, Aguert et al. have proved that irony occurs more often in the digital medium, where it is used as compensation for the distance typical for indirect (online) communication. Thus, it turns out that irony can be adapted successfully to changing interaction conditions. Furthermore, the study also provides evidence that adolescence is a key stage in the development of irony use skills. Meanwhile, the research of Anna Milanowicz and Piotr Kałowski (both from the University of Warsaw) focuses on the variable of gender and its role in understanding and using irony. The authors trace the structure of participation in discourse as a function of the participant structure. They show that women respond more often with irony to irony from men than from women. This difference is due to the self-image structure that is activated in a situation of comparing oneself with others. Beliefs about oneself and others affect the understanding of signals from other people and our responses to them as regards irony as well, as shown in how the participant structure affects the use of this form of nonfigurative language. What is more, the authors present an experiment they are currently conducting which tests the hypothesis of gender affecting irony comprehension and use in a research procedure involving video footage of ironic utterances (as stimuli) and recordings of the subjects' verbal responses as data. Taken together, the above two papers explore the occurrence of irony in an anonymous, purely textual context on the one hand and in a social situation of a meeting between specific representatives of social groups on the other.

The next two studies focus on the role of individual differences between users of verbal irony. Paying attention to the characteristics of people producing ironic utterances also provides valuable information on irony as a phenomenon and why we use it. In his paper (included in this issue) "I understand you, so I'll not hurt you with my irony: Correlations between irony and emotional intelligence", Michał Bajerski (University of Warsaw) investigates how emotional intelligence affects the use of irony. It turns out a negative correlation exists between them: A higher level of emotional intelligence is a predictor of less frequent use of irony and self-irony. Awareness and understanding of the emotions of others seems to lead to avoidance of irony, possibly due to its rather negative, critical character. The author explains that people with high emotional intelligence could feel more comfortable using less ambiguous means of communication. The study by Magda Gucman (University of Warsaw), presented in the paper "The role of individual differences and situational factors in perception of verbal irony," examines a series of variables related to both the participant structure (here: the position in the social hierarchy) and individual traits of subjects (fear as a trait and as a state and social competence) as well as the actors' personal responsibility for an event which the given ironic utterance criticizes. The results of this study show that irony is perceived as funnier and more intelligent than direct 
criticism. However, being the agent of the situation to which the ironic comment refers led to higher subjective assessments of the ironic remark's critical quality. It is interesting, however, that in the case of blame, irony was still perceived as funny. Furthermore, irony was seen as generally gentler when it came from someone higher in the social hierarchy than its addressee. In such a situation, irony seems to tone down the criticism and disapproval which someone with a higher status can express with social approval. People with a higher level of fear also interpreted irony as more negative and critical, which is compatible with the psychological understanding of fear as a tendency to focus on danger and to automatically choose more negative interpretations of ambiguous and unclear stimuli. On the other hand, the study did not show any significant influence of social competence on understanding irony. Thus, the work of Bajerski and the work of Gucman show a wide range of potential factors involved in situations of irony use. It is surprising that irony is so widespread in daily life and its occurrence is seen as natural, despite its enormous complexity revealed by empirical research.

The present issue also includes papers that concentrate on irony in a developmental perspective, with the aim of investigating how and at what stage of life the ability to understand and produce irony is acquired. The study by Maria Zajączkowska (University of Warsaw), described in the paper "Influence of voice intonation on understanding irony by Polish-speaking preschool children", focuses on the role of prosodic indicators in irony comprehension. Irony is characterized by a special, distinct tone of voice and intonation that can provide a pointer for interpreting ironic comments (Cutler, 1974). The five-year-olds in the study relied more strongly on prosodic indicators of irony in discovering ironic meanings than did six-year-olds, who were better at using information coming from the situational context. Moreover, a qualitative analysis of the children's responses showed that interpretations of comments expressed in an ironic voice were more often related to the psychological states of the speakers. This is suggested by the fact that understanding paralinguistic signals such as tone of voice or intonation is one of the elements of attributing specific states of mind to others (the theory of mind, ToM). The paper by Anna M. Kołodziejczyk (Jagiellonian University, Kraków) and Sandra L. Bosacki (Brock University, St. Catharines), entitled "Young school-aged children's use of direct and indirect persuasion: Role of intentionality understanding", which also considers ToM in a developmental perspective, discusses the use of persuasion by children aged from five to seven years. The study conducted by the authors showed that children used persuasive strategies more often toward their parents, that is, in situations of asymmetrical status. The persuasive strategies they used, however, were direct in character, meaning that they communicated their intentions and arguments in an unequivocal way. Older children in the studied group, however, used more advanced strategies which indicated greater awareness of the expectations and 
mental states of their interlocutors as well as a greater ability to adjust to them. In other words, the older children showed a more developed ToM. As the study presented here indicates, understanding irony is a process acquired during development, and one that is founded upon a number of other mental skills.

The next area of research outlined in this issue is the role of bilingualism in irony comprehension. The paper "Comprehension of ironic utterances by bilingual children" by Natalia Banasik and Kornelia Podsiadło (both from the University of Warsaw) presents a study on irony comprehension by bilingual children. Investigating the level of ToM in six-year-old bilingual children, the authors show that, already at that age, children are able to find the true meaning concealed behind the ironic form of an utterance with a high success rate. The authors suggest that this skill is related to the development of ToM, facilitated by higher metalinguistic skills acquired in the process of growing up in a bilingual, and thus more linguistically complex, environment. Furthermore, the study did not find differences in understanding sarcastic and nonsarcastic irony, which the authors attribute to the influence of cultural differences between the populations of English-speaking (mainly American) and Polish-speaking children. Our issue concludes with a paper by Katarzyna Bromberek-Dyzman and Karolina Rataj (both from the Adam Mickiewicz University, Poznań), "Do they get irony in their non-native language?" The authors studied the process of irony comprehension in foreign languages by adults in the context of limited time allowed for responding. The subjects processed irony more slowly than literal utterances, in both their native and the foreign language, which indicates that irony imposes a greater cognitive burden.

Each of the texts presented here opens up new questions on figurative language processing, in this case irony. In the next issue (to be published in 2017), we will discuss research on metaphors. Happy reading!

\section{References}

Colston, H. \& Gibbs, R. (2007). A brief history of irony. In R. Gibbs \& H. Colston (Eds.), Irony in Language and Thought: A Cognitive Science Reader (pp. 3-21). Mahwah, NJ: Lawrence Erlbaum Associates.

Cutler, A. (1974). On saying what you mean without meaning what you say. In M. Galy, R. Fox, \& A. Bruck (Eds.), Papers from the Tenth Regional Meeting, Chicago Linguistic Society (pp. 117-127). Chicago, IL.: CLS.

Kreuz, R.J. \& Roberts, R.M. (1993). On satire and parody: The importance of being ironic. Metaphor and Symbol, 8 (2), 97-109.

Philips, S.U. (1972). Participant structures and communicative competence: Warm Springs children in community and classroom. In C.B. Cazden, V.P. John, \& D. Hymes (Eds.), Functions of Language in the Classroom (pp. 370-394). New York: Teachers College Press. 
Shugar, G.W. (1995). Dyskurs dziecięcy. Rozwój w ramach struktur społecznych [Child Discourse. Development in the Framework of Social Stuctures]. Warsaw: Energeia.

Tannen, D. (1981). Ethnicity as conversational style. Discourse Processes, 4 (3). 221-238.

Wampole, Ch. (2012). How to Live Without Irony, The New York Times. Retrieved from: http://opinionator.blogs.nytimes.com/2012/11/17/ how-to-live-without-irony/?_r=0 